\title{
THE EFFECT OF CELL-FREE FLUIDS PREPARED FROM CULTURES OF HUMAN AND ANIMAL ENTERO- PATHOGENIC STRAINS OF ESCHERICHIA COLI ON LIGATED INTESTINAL SEGMENTS OF RABBITS AND PIGS
}

\author{
H. Williams Smith and C. L. Gyles* \\ Animal Health Trust, Stock, Essex
}

\section{Plate XXXVI}

SMITH AND HALLS (1967a) compared the effect of enteropathogenic strains of Escherichia coli from different sources on ligated intestinal segments of several animal species. The strains isolated from human beings and some of the strains from pigs dilated segments of rabbit intestine, but in a rather inconstant fashion; the strains from cattle and sheep failed to dilate rabbit intestine. Only the pig strains dilated pig intestine. The substance responsible for this dilatation, the enterotoxin, was obtained from cultures of all the pig strains in a cell-free state (Smith and Halls, 1967b). Similar cell-free preparations from the strains of human, bovine and ovine origin did not dilate pig intestine.

Gyles and Barnum (1969) reported an apparently additional enterotoxin produced by some enteropathogenic pig strains; unlike the more stable enterotoxin reported by Smith and Halls (1967b) and referred to subsequently as ST, this enterotoxin was heat-labile, antigenic and precipitable by ammonium sulphate and it was subsequently referred to as LT. Despite these differences, recent work with some strains has shown that production of LT and ST is controlled by transmissible plasmids and it is probable that LT and ST are two forms of essentially the same enterotoxin (Smith and Gyles, 1970).

The purpose of the present paper is to report on the activity of LT- and ST-type preparations derived from culture products of human, porcine, bovine and ovine enteropathogenic strains on ligated segments of rabbit intestine. Observations on the effect of LT-type preparations of the human, bovine and ovine strains on pig intestine are also included, the effect of ST-type preparations of these strains on pig intestine having previously been studied by Smith and Halls (1967b).

\section{MATERIALS AND METHODS}

LT-type enterotoxin preparations consisted of sterile cell-free lysates of $E$. coli grown on solid media, whereas ST-type preparations consisted of sterile, cell-free fluids expressed from soft agar cultures and then held at $65^{\circ} \mathrm{C}$ for $15 \mathrm{~min}$. Live cultures were tested after incubation of the test strains in nutrient broth for $24 \mathrm{hr}$ at $37^{\circ} \mathrm{C}$.

Received 26 Nov. 1969; accepted 8 Jan. 1970.

* Research Fellow, Canadian Medical Research Council. 
The methods of preparing the enterotoxins and of producing antisera have been described previously; so has the method of testing them in ligated intestinal segments of pigs (Smith and Gyles). They were tested in a similar manner in rabbits, segments approximately $10 \mathrm{~cm}$ long being used for testing cultures and LT-type preparations, and segments approximately $15 \mathrm{~cm}$ long for testing ST-type preparations. The untreated control segments that separated the test segments were approximately $4 \mathrm{~cm}$ long. In each rabbit, 6-8 segments were used for tests, the most anterior one commencing $30 \mathrm{~cm}$ from the stomach and the most distal ending $10 \mathrm{~cm}$ from the caecum. The doses of live cultures and of LT- and ST-type preparations employed in the rabbit tests were 1, 3-5 and $9 \mathrm{ml}$ respectively.

Some of the strains of $E$. coli used had received the plasmid controlling enterotoxin production, Ent, during mixed culture with pig-enteropathogenic donor strains (Smith and Halls, 1968). These strains were recognised by their ability to dilate ligated pig intestine; they are identified by their original number followed by the number, in brackets, of the donor strain, and the symbol Ent + . Strains that had not received Ent in these mixed cultures are similarly identified and carry the suffix Ent ${ }^{-}$. Strains of human origin are given the prefix $H$, porcine strains $P$, bovine strains $B$, ovine strains $S$ and fowl strains $F$.

\section{RESULTS}

\section{Tests in ligated segments of rabbit intestine}

\section{Studies with porcine strains}

LT preparations of two wild enterotoxigenic strains of $E$. coli, antigenic formulae O138:K81,88ac and O149:K91,88ac, each provoked a marked dilatation of rabbit intestine; the volumes of fluid that accumulated in segments into which they had been injected were 35 and $55 \mathrm{ml}$ respectively. Similar results were obtained with LT preparations of strains into which the Ent plasmid had been transmitted from donor strains that produced both LT and ST. The recipient strains in these experiments were F11(O18:K ?) and $\mathrm{K} 12 \mathrm{~F}^{-}$and the donor strains, P103(O8:K87,88ab), P233(O8:K87,88ac), $\mathrm{P} 155(\mathrm{O} 149: \mathrm{K} 91,88 \mathrm{ac})$ and P307,88-(O8:K87) which had lost its K88 antigen. The volumes of fluid provoked by the LT preparation of one of these strains, F11(P307,88-)Ent ${ }^{+}$, in six tests in different rabbits were 15, 22, 24, 27, 40 and $44 \mathrm{ml}$. LT preparations of an F11(P307,88-)Ent - strain were tested in three of these six rabbits; no fluid at all accumulated in the segments into which they were injected. Similarly, no fluid accumulated in segments given LT-type preparations of two F11 strains that had received Ent from two antigenically dissimilar strains shown to produce ST and not LT in ligated segment tests in pigs (Smith and Gyles, 1970). The results of some of the tests referred to above are illustrated in fig. 1.

Tests were also performed with ST preparations of most of the above strains into which Ent had been transmitted; all these preparations dilated pig intestine. The reactions in rabbit intestine were slight or, in most cases, negative. However, an ST preparation of strain F11(P155)Ent +, known to be a good enterotoxin producer, strongly dilated rabbit intestine. For example, $28 \mathrm{ml}$ of fluid accumulated in a ligated segment treated with such a preparation; no fluid was found in a neighbouring segment that had received an injection of an ST preparation of F11(P155)Ent -

LT-type preparations of an 0139:K82 strain that had been isolated from 
a pig suffering from oedema disease consistently dilated rabbit intestine, although preparations of this strain had failed to dilate ligated pig intestine when tested as live culture, ST, or LT. In nine tests in nine different rabbits, the volume of fluid that accumulated in each of the test segments was 7-25 ml (median $17 \mathrm{ml}$ ). LT produced by two of another three epidemiologically unrelated $0139: K 82$ strains also dilated rabbit intestine on most of the four occasions on which each one was tested; the third did not. As we found with the O139:K82 strain previously referred to, injections of live cultures, or LT or ST preparations of these three strains did not dilate pig intestine. LT-type preparations of four non-pathogenic strains isolated from the faeces of different healthy pigs were each tested in ligated segments in rabbits on five occasions. The preparation from one strain caused dilatation on three occasions and from another two on one occasion; that from the fourth failed to cause dilatation of the rabbit intestine. These preparations as well as ST-type preparations and live cultures of these four strains did not dilate ligated pig intestine.

\section{Studies with bovine and ovine strains}

LT-type preparations of seven epidemiologically unrelated strains of $E$. coli enteropathogenic for calves, three of antigenic formula $\mathrm{O} 101: \mathrm{K}$ ?, two of antigenic formula $\mathrm{O} 9: \mathrm{K} 9$, one of antigenic formula $\mathrm{O} 8: \mathrm{K}$ ? and an untypable strain, all failed to dilate rabbit intestine. LT from an O8:K ? strain enteropathogenic for lambs also proved negative in similar tests. In contrast, $\mathrm{LT}$ of an $\mathrm{O} 26: \mathrm{K} 60: \mathrm{H}$ ? strain isolated from the faeces of a calf provoked the accumulation of $2,32,34$ and $42 \mathrm{ml}$ of fluid in four ligated segments of different rabbits in which it was tested. This strain had consistently failed to dilate calf intestine.

\section{Studies with human strains}

The results of testing LT-type preparations of 56 human strains of $E$. coli in ligated intestinal segments of rabbits are summarised in table I. A test in which at least $6 \mathrm{ml}$ of fluid accumulated in the ligated segment was recorded as positive; in most tests recorded as negative no fluid was present. As a group, the strains generally regarded as enteropathogenic more commonly yielded LT-type preparations that gave positive reactions than did those regarded as non-enteropathogenic. The preparations of many of the enteropathogenic strains caused dilatation fairly consistently. This was particularly so in the case of the five $\mathrm{O} 26$ strains. The volume of fluid provoked by preparations of one of these strains tested on ten occasions was 9-30 ml (median $16 \mathrm{ml}$ ). In contrast, preparations of three 0126 strains failed to cause dilatation on each of the eight occasions on which they were tested. Among the nonenteropathogenic strains, the O6 strains as LT preparations were outstandingly good at causing dilatation. The volume of fluid that accumulated in the 16 segments in which LT-type preparations of four of these strains were tested on four occasions was $12-33 \mathrm{ml}$ (median $24 \mathrm{ml}$ ).

Thermolability of $L T$. The effect of temperature on LT-type preparations of 14 human enteropathogenic strains belonging to one or other of six different 
serotypes was assessed. Their activity was destroyed completely by holding them at $80^{\circ} \mathrm{C}$ for $15 \mathrm{~min}$., but it was unaffected by exposure to heat at $60^{\circ} \mathrm{C}$ for $30 \mathrm{~min}$. It was usually destroyed or markedly reduced by heat at $65^{\circ} \mathrm{C}$ for $15 \mathrm{~min}$. A similar degree of heat resistance was possessed by LT-type preparations of two $06: \mathrm{K} 13: \mathrm{H} 1$ strains and one $0139: \mathrm{K} 82$ strain, the only other strains tested.

Serological neutralisation of LT. The specific neutralising effect of antisera prepared in pigs against live organisms on the dilating effect produced in rabbit

TABLE I

The ability of LT-type preparations of human faecal strains of Escherichia coli to dilate ligated segments of rabbit intestine

\begin{tabular}{|c|c|c|c|c|}
\hline $\begin{array}{l}\text { Antigenic structure } \\
\text { of test strain }\end{array}$ & $\begin{array}{l}\text { Classification on } \\
\text { basis of antigenic } \\
\text { structure }\end{array}$ & $\begin{array}{l}\text { Associated clinical } \\
\text { state at time of } \\
\text { isolation }\end{array}$ & $\begin{array}{c}\text { Number } \\
\text { tested }\end{array}$ & $\frac{\text { No. of tests positive* }}{\text { No. of tests performed }}$ \\
\hline $\begin{array}{l}\mathrm{O} 26: \mathrm{K} 60: \mathrm{H} 11 \text { or } \mathrm{H}- \\
\text { O55:K } 59: \mathrm{H} 6 \text { or } \mathrm{H} 7 \\
\text { O86:K }: \mathrm{H} 10 \\
\text { O111:K } 58: \mathrm{H} 2 \\
\text { O119:K69:H6 } \\
\text { O125:K } 70: \mathrm{H} 21 \\
\text { O126:K } 71: \mathrm{H} 2 \\
\text { O127:K63:H4 } \\
\text { O128:K67:H2 } \\
\text { O128:K67:H2 }\end{array}$ & Enteropathogenic & $\begin{array}{l}\text { Neonatal diarrhoea } \\
\text { Neonatal diarrhoea } \\
\text { Neonatal diarrhoea } \\
\text { Neonatal diarrhoea } \\
\text { Neonatal diarrhoea } \\
\text { Neonatal diarrhoea } \\
\text { Neonatal diarrhoea } \\
\text { Neonatal diarrhoea } \\
\text { Neonatal diarrhoea } \\
\text { Healthy adult }\end{array}$ & $\begin{array}{l}5 \\
\\
3 \\
1 \\
2 \\
2 \\
3 \\
3 \\
1 \\
2 \\
1\end{array}$ & $\begin{array}{l}10 / 10,6 / 6,12 / 13, \\
21 / 24,12 / 20 \\
4 / 9,2 / 5,1 / 6 \\
0 / 8 \\
3 / 4,2 / 4 \\
12 / 14,0 / 5 \\
5 / 5,9 / 14,2 / 4 \\
0 / 8 \text { (3 strains) } \\
1 / 8 \\
10 / 18,0 / 6 \\
4 / 4\end{array}$ \\
\hline $\begin{array}{l}\text { O6:K13:H1 } \\
\text { O6:K13:H1 } \\
\text { Untyped, but not } \\
\text { belonging to sero- } \\
\text { types listed above }\end{array}$ & $\begin{array}{c}\text { Not } \\
\text { enteropathogenic }\end{array}$ & $\begin{array}{l}\text { Neonatal diarrhoea } \\
\text { Healthy adult } \\
\text { Healthy adults }\end{array}$ & $\begin{array}{r}4 \\
2 \\
27\end{array}$ & $\begin{array}{l}4 / 4 \text { ( } 3 \text { strains), } 0 / 4 \\
5 / 5,2 / 4 \\
3 / 4,2 / 4 \text { ( } 3 \text { strains), } \\
\quad 1 / 4 \text { (5 strains), } 0 / 4 \\
\quad \text { (18 strains) }\end{array}$ \\
\hline
\end{tabular}

* Positive $=$ segment contained at least $6 \mathrm{ml}$ of fluid.

ligated intestinal segments by LT-type preparations of human strains of $E$. coli is indicated in table II. Identical preparations were tested in adjacent segments, one mixed with pre-vaccinal serum and one mixed with postvaccinal serum (see Smith and Gyles). Each antiserum completely neutralised the enterotoxic activity of the LT-type preparation of the homologous strain against which it had been made, but had no effect on the dilating ability of preparations of the strains that belonged to other serotypes. It is noteworthy that the O26:K60:H11 antiserum neutralised preparations of the strain against which it had been made and preparations of only one of three other strains of this serotype. The antiserum also failed to neutralise a preparation of the $\mathrm{O} 26: \mathrm{K} 60: \mathrm{H}$ ? strain that had been isolated from calf faeces (see previously). Another non-motile human strain of this serotype yielded preparations whose dilating effect was completely neutralised by all samples of normal pig and rabbit serum with which they were tested. Antiserum prepared against an enterotoxigenic pig strain did not neutralise the activity of LT-type preparations 
of the human enteropathogenic strains, two $06: \mathrm{K} 13: \mathrm{H} 1$ strains and an 0139:K82 non-enterotoxigenic pig strain; it effectively neutralised LT preparations of all the pig enterotoxigenic strains with which it was tested.

\section{Tests in ligated segments of pig intestine}

The LT-type preparations of the five bovine enteropathogenic strains, and similar preparations of the one bovine enteropathogenic strain and of

TABLE II

Serological neutralisation of the dilating effect of LT preparations of human enteropathogenic strains of Escherichia coli on ligated segments of rabbit intestine

\begin{tabular}{|c|c|c|c|c|c|c|}
\hline \multirow{2}{*}{$\begin{array}{c}\text { LT-type } \\
\text { preparation of } \\
\text { strain of } \\
\text { serotype* }\end{array}$} & \multicolumn{6}{|c|}{ Neutralising effect $\dagger$ of antiserum prepared from strain of serotype } \\
\hline & $\begin{array}{c}\mathrm{O} 26: \mathrm{K} 60: \mathrm{H} 1 \\
(1)^{*}\end{array}$ & $\mathrm{O} 55: \mathrm{K} 59: \mathrm{H} 7$ & $\mathrm{O} 111: \mathrm{K} 58: \mathrm{H} 2$ & O119:K14:H6 & $\mathrm{O} 125: \mathrm{K} 70: \mathrm{H} 21$ & $\mathrm{O} 128: \mathrm{K} 67: \mathrm{H} 2$ \\
\hline $\begin{array}{l}\text { O26:K60:H11 } \\
\text { strain } 1 \\
\text { strain } 2 \\
\text { strain } 3 \\
\text { strain } 4 \\
\text { O55:K57:H7 } \\
\text { O111:K58:H2 } \\
\text { O119:K } 14: \mathrm{H} 6 \\
\text { O125:K70:H21 } \\
\text { O128:K67:H2 }\end{array}$ & $\begin{array}{l}+ \\
\pm \\
= \\
- \\
- \\
= \\
-\end{array}$ & $\begin{array}{l}- \\
\cdots \\
\cdots \\
\pm \\
= \\
-\end{array}$ & $\begin{array}{l}- \\
\cdots \\
\cdots \\
+ \\
\pm \\
- \\
-\end{array}$ & $\begin{array}{l}- \\
\cdots \\
\cdots \\
= \\
\pm \\
\pm \\
-\end{array}$ & $\begin{array}{l}- \\
\cdots \\
\cdots \\
- \\
- \\
\pm \\
\pm\end{array}$ & $\begin{array}{l}- \\
\cdots \\
\cdots \\
= \\
= \\
- \\
+\end{array}$ \\
\hline
\end{tabular}

* The same strain of each serotype was used for making the LT-type preparation and the antiserum. Four O26:K60:H11 strains, however, were tested, the antiserum being prepared from strain 1.

$\dagger+=$ Neutralisation; $-=$ no neutralisation; $\ldots=$ not tested.

five of the human enteropathogenic strains that had been tested in rabbits failed to dilate ligated segments of pig intestine; LT preparations of the human strains used in these studies had been found to dilate rabbit intestine. The tests with some of these preparations are illustrated in fig. 2 . Live cultures of the bovine and ovine strains had been found to dilate ligated segments of calf and lamb intestine consistently (Smith and Halls, 1967a).

\section{DisCUSSION}

The fact that LT-type preparations of Escherichia coli that had received the plasmid controlling production of enterotoxin active in the pig model (pig enterotoxin) dilated ligated rabbit intestine, whereas similar preparations of the corresponding Ent - strains were inactive in the ligated rabbit intestine, indicates that the pig enterotoxin itself was responsible for the dilatation produced by the Ent + strains in both models. However, although an occasional positive response occurring in ligated rabbit intestine might be dismissed as being due to some extraneous cause, the positive reactions consistently produced by some non-enterotoxigenic pig strains, particularly those of serotype 
O139:K82, revealed quite clearly that rabbit intestine can be dilated by products of pig $E$. coli strains other than the pig enterotoxin.

Consistently negative results were obtained in rabbit and pig ligated intestine with LT-type preparations of the bovine and ovine enterotoxigenic strains and in pig intestine with LT-type preparations of the human enteropathogenic strains; this indicates either that the intestine of these animals is not susceptible to enterotoxin produced by these strains or that the enterotoxin produced is not present in LT-type preparations of these strains. Whether the substance in the preparations of the human enteropathogenic strains that caused dilatation of rabbit intestine is indeed an enterotoxin that provokes diarrhoea in babies infected with these strains is clearly questionable. As far as animal strains are concerned, the relevance of a positive reaction in ligated rabbit intestine can be assessed by performing similar experiments in the species of animal from which the particular strains originated and by administering live cultures and material suspected of containing enterotoxin by mouth to such animals. These approaches in the case of human strains are largely impossible to pursue.

Certainly, LT-type preparations of human enteropathogenic strains dilated ligated rabbit intestine more commonly than did those of the human nonenteropathogens. However, there were some notable exceptions in this respect as far as the human enteropathogens were concerned. If the positive reactions given by the enteropathogens were really responses to human enterotoxin, then the evidence from the antiserum-neutralisation studies indicates that not only each serotype, but even strains within the same serotype, may produce a different enterotoxin. This contrasts markedly with the situation existing with pig enteropathogenic strains; here the results of antiserum-neutralisation tests reveal that the LT substances produced by different serotypes are identical. The identical nature of the LT component produced by pig strains, however, may represent a special situation because of the transmissible nature of the Ent plasmid in these strains.

An assessment of the significance of the observations reported in this paper must take into consideration the studies of Taylor and Bettelheim (1966) on the enterotoxigenicity of human strains of $E$. coli. The extremely labile enterotoxin described by these workers would almost certainly be inactivated by our methods of preparing and handling LT-type preparations. It is probable then that the substance (or substances) in our preparations that dilated rabbit intestine was not the enterotoxin of Taylor and Bettelheim. The ultimate elucidation of the significance of the enterotoxic substances studied in the present work probably awaits the development of a more satisfactory method of investigation than that provided by the ligated rabbit intestine.

\section{SUMMARY}

The relatively labile (LT) form of the enterotoxin produced by pig-enteropathogenic strains of Escherichia coli strongly dilated ligated segments of rabbit intestine; the more stable (ST) form had a weaker effect. Dilatation was also produced by LT-type preparations of some non-enteropathogenic pig strains. 


\section{ENTEROPATHOGENIC ESCHERICHIA COLI}

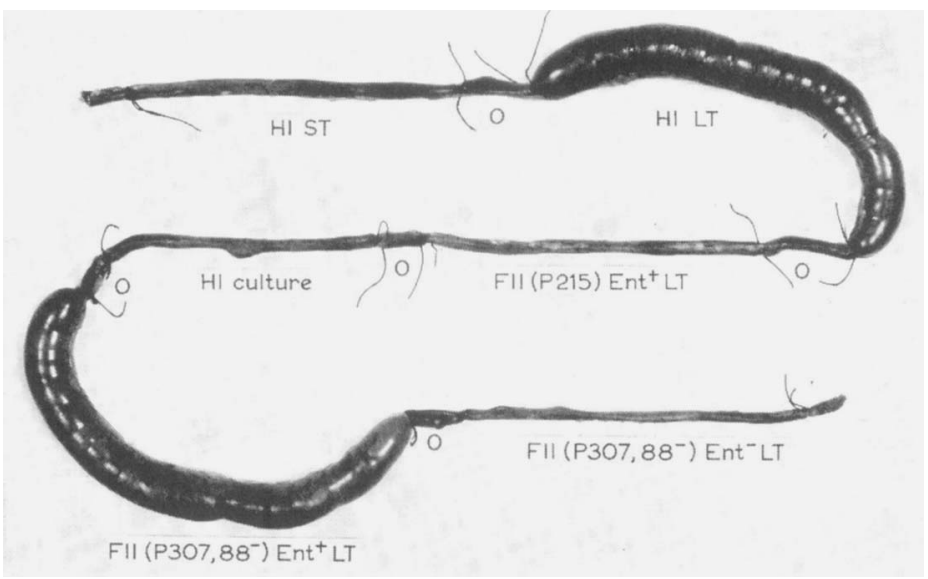

FIG. 1.-Ligated segments of rabbit intestine after injection of (i) LT and ST preparations and live cultures of the human enteropathogen $\mathrm{HI}$, and (ii) LT preparations of strain F11 into which Ent plasmids had or had not been transmitted. In tests in pig intestine, F11(P307,88-)Ent ${ }^{+}$ had been found to produce LT and ST; F11(P215)Ent - had been found to produce ST only. In this rabbit, the live culture of $\mathrm{HI}$ gave a negative reaction; inconsistency of reaction is a feature of live cultures of this strain in tests in rabbits. $0=$ Control untreated segments. $\times c .0 \cdot 3$.

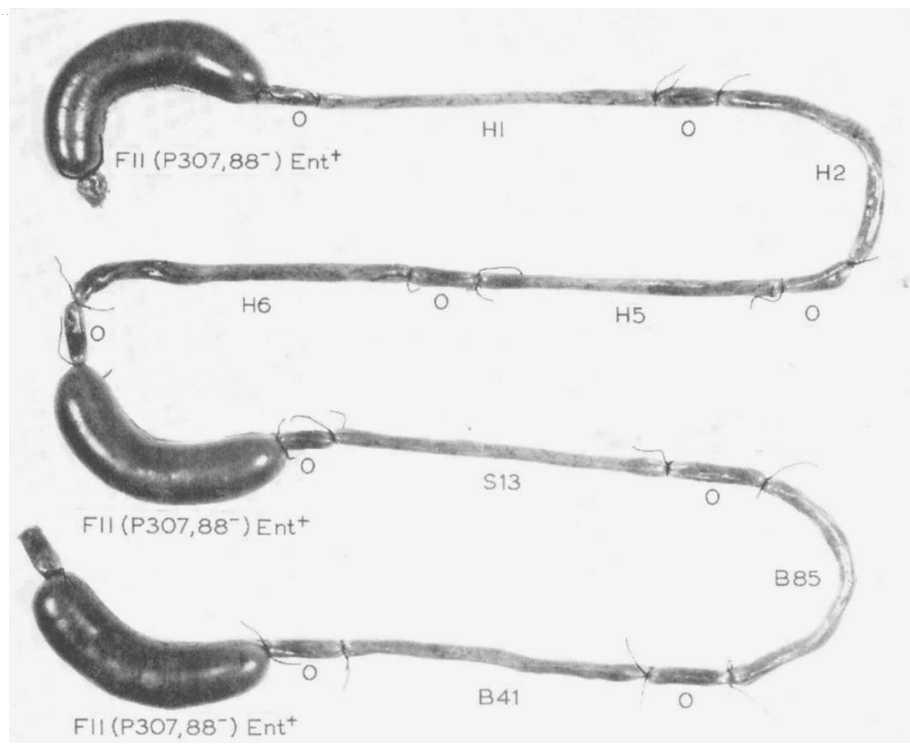

FIG. 2.-Ligated segments of pig intestine after injection of LT-type preparations of four human enteropathogenic strains, $\mathrm{H} 1, \mathrm{H} 2, \mathrm{H} 5$ and $\mathrm{H} 6$, two bovine enteropathogenic strains, B41 and B85, and the ovine enteropathogenic strain, S13. An LT preparation of FI1(P307,88-)Ent ${ }^{+}$ that had received the Ent plasmid from the pig enteropathogenic strain, P307,88-, is used as a positive control. $\times 0 \cdot 2$. 
Similar preparations of cultures of bovine and ovine enteropathogenic strains failed to dilate rabbit and pig intestine; those of the human strains tested also failed to dilate pig intestine.

LT-type preparations of many of the human enteropathogenic strains dilated rabbit intestine; so did a smaller proportion of the non-enteropathogenic human strains tested. The dilating ability of these preparations was destroyed, or markedly reduced, by exposure to heat at $65^{\circ} \mathrm{C}$ for $15 \mathrm{~min}$. The activity was also neutralised by antiserum in a serotype-specific or strainspecific manner.

We are grateful to Miss Diane Poulton, Miss Carole Smith and Miss Marion White for their capable technical help, and to Mr L. J. Abbott, Mrs Esther Johnson, Miss Margaret Linggood, Dr Ida Ørskov, Dr K. C. Sellers and Mr W. J. Sojka for help and assistance in a variety of ways. The expenses of this work were kindly defrayed by a grant from the Agricultural Research Council.

\section{REFERENCES}

Gyles, C. L., AND Barnum, D. A. 1969. J. Infect. Dis., 120, 419.

Smith, H. W., ANd Halls, Sheila . 1967a. J. Path. Bact., 93, 499.

" " " . . 1967b. Ibid., 93, 531.

" " " $\quad$ • . 1968. J. Gen. Microbiol., 52, 319.

SMITH, H. W., AND Gyles, C. L. • $\quad$ • 1970. J. Med. Microbiol., 3, 387.

TAylor, JoAn, AND Bettelheim, K. A. . 1966. J. Gen. Microbiol., 42, 309. 